\title{
Fenologia de Paratecoma peroba (Bignoniaceae) em uma floresta estacional semidecidual do norte fluminense, Brasil
}

\author{
Phenology of Paratecoma peroba (Bignoniaceae) in a seasonal \\ semideciduous forest of Northeastern Rio de Janeiro, Brazil \\ Beatriz Lacerda Almeida Lins $^{1,2}$ \& Marcelo Trindade Nascimento ${ }^{1,3}$
}

\begin{abstract}
Resumo
Estudos fenológicos auxiliam na compreensão do comportamento das espécies em resposta a alterações no ambiente e são também importantes para a conservação e manejo das mesmas. A fenologia de Paratecoma peroba (Record \& Mell) Kuhlm. foi estudada no período de outubro/2005 a dezembro/2007 na Mata do Carvão (Estação Ecológica Estadual de Guaxindiba), São Francisco do Itabapoana, RJ. As observações foram realizadas mensalmente, exceto durante a fase de floração que ocorreram em intervalos quinzenais. Acompanharam-se 42 indivíduos que apresentaram comportamento fenológico sazonal, com a senescência foliar ocorrendo no início da estação seca e a queda foliar entre meados e final desta mesma estação. O brotamento de novas folhas ocorreu no início da estação chuvosa. As percentagens de Fournier encontradas para as fenofases reprodutivas foram baixas e somente indivíduos com DAP > $16 \mathrm{~cm}$ apresentaram botões florais. No final da estação seca de 2005, os indivíduos apresentaram fenofases reprodutivas, com a floração ocorrendo na transição da estação seca para chuvosa e a frutificação foi longa (cerca de um ano) tendo início na estação chuvosa (novembro), com os frutos dispersando as sementes aladas no início da estação chuvosa seguinte. Nos anos seguintes, 2006 a 2008, não foi observado evento de floração. A espécie foi caracterizada como decídua, apresentando periodicidade de floração supra-anual.
\end{abstract}

Palavras chave: brotamento, botões florais, fenologia, Mata atlântica, senescência.

\begin{abstract}
Phenological studies help the understanding of species behavior as a result to environmental changes and are also important for species conservation and management. The phenology of Paratecoma peroba (Record \& Mell) Kuhlm. was studied from October/2005 to December/2007 in Mata do Carvão (Guaxindiba Ecological Station), São Francisco do Itabapoana, RJ. The observations were done in one-month intervals, except the flowering that was done at two week intervals. Forty two individuals were systematically observed. They showed phenological pattern characterized by the seasonal occurrence of the phenophases, with leaf senescence occurring at the beginning of the dry season and the leaf fall between the middle and the end of this season. New leaves were flushed at the beginning of the wet season. Foumier intensity values were low for reproductive phenophases and only trees with diameter at breast height $(\mathrm{dbh})>16 \mathrm{~cm}$ sprouted flowers. Reproductive phenophases started at the end of dry season of 2005 , with flowering occurring in the transition of the dry to the wet season. Fruiting was long (one year), starting at the beginning of the wet season (November) with dispersion of the anemocoric seeds occurring at the beginning of the following wet season. However, in the following years (2006-2008), flowering did not occur. This species was classified as deciduous, with a supra-annual flowering period.
\end{abstract}

Key words: flushing, flower buds, phenology, Atlantic forest, shedding.

\section{Introdução}

A fenologia é o estudo da ocorrência de eventos biológicos repetitivos e das causas de sua ocorrência em relação às forças seletivas bióticas e abióticas. Através desse estudo permite-se avaliar a inter-relação entre as fases caracterizadas por esses eventos biológicos, dentro de uma mesma ou entre distintas espécies (Talora \& Morellato 2000).

\footnotetext{
${ }^{1}$ Universidade Estadual do Norte Fluminense, Laboratório de Ciências Ambientais, Av. Alberto Lamego 2000, 28013-600, Campos dos Goytacazes, RJ, Brasil. ${ }^{2}$ Bolsista de Iniciação Científica, CNPq

${ }^{3}$ Bolsa de produtividade científica CNPq, autor para correspondência: mtn@uenf.br
} 
As pesquisas fenológicas são frequentemente associadas a variáveis climáticas e fatores bióticos (Dias \& Oliveira-Filho 1996; Talora \& Morellato 2000; Reys et al. 2005). O periodismo, a sazonalidade, e o sincronismo também têm sido uma constante preocupação dos estudos fenológicos (Newstrom et al. 1994; Dias \& Oliveira-Filho 1996). Segundo Newstrom et al. (1994), o período de um evento fenológico é uma resultante do tempo decorrido entre o episódio e seu intervalo. A sazonalidade é definida como sendo uma associação temporal entre o evento fenológico e determinado mês ou determinada estação do ano e o sincronismo é definido como a ocorrência simultânea da mesma fenofase em todas ou, pelo menos, na maioria das unidades de estudo analisadas. Alguns estudos têm sido conduzidos entre os diferentes estratos ou estágios sucessionais em florestas (Frankie et al. 1974; Andreis et al. 2005), contribuindo com informações sobre os distintos períodos de crescimento e reprodução das espécies vegetais e, consequentemente, sobre a oferta de recursos para a fauna local (Reys et al. 2005).

Estudos fenológicos podem ser empregados como ferramenta para conservação de recursos vegetais florestais (Mantovani et al. 2003; Santos \& Takaki 2005), através de informações, por exemplo, sobre o período reprodutivo e não-reprodutivo das espécies vegetais e pico de produção de frutos/sementes. Segundo esses mesmos autores, o conhecimento da fenologia reprodutiva das espécies a serem manejadas, frente às exigências dos planos de manejo das formações florestais, é de fundamental importância para uma melhor seleção de matrizes para coleta de sementes.

O Brasil é o maior centro de diversidade da família Bignoniaceae, com 55 gêneros e 316 espécies (Gentry 1980), distribuídas principalmente entre as tribos Bignonieae, Crescentieae, Jacarandeae e Tecomeae (Olmstead et al. 2009). Esta família tem sido bem estudada em relação à fenologia e morfologia floral (Gentry 1974; Scudeller et al. 2008; Alcântara \& Lohmann 2010). Gentry (1974) considerou que a diversidade fenológica exibida pelas espécies tropicais de Bignoniaceae seria consequiência da adoção de diferentes estratégias reprodutivas, permitindo o compartilhamento de polinizadores entre elas. Estes estudos estão concentrados principalmente em espécies de dois grandes clados (Bignonieae e Crescentiina) que juntos correspondem a cerca de $80 \%$ das espécies de Bignoniaceae (Olmstead et al. 2009).

Entre as Bignoniáceas arbóreas de floresta estacional podemos destacar Paratecoma peroba (Record \& Mell) Kuhlm endêmica do litoral brasileiro e praticamente extinta (Gentry 1992) que ocorre do sul da Bahia ao norte do estado do Rio de Janeiro (Nascimento \& Lima 2008). Este gênero, que atualmente pertence ao clado "Tabebuia alliance" (Olmstead et al.2009), é monotípico. Esta espécie é popularmente conhecida como peroba-de-campos, peroba-amarela ou peroba-branca (ES), ipê (BA), perobinha ou ipê-rajado (MG) (Lorenzi 2000) e foi no passado considerada a madeira comercial mais importante do estado do Rio de Janeiro, sendo utilizada em construções comerciais no estado e no acabamento de casas e em mobiliário de luxo. Até hoje poucos estudos botânicos (dos Santos \& Miller 1992) e ecológicos (Villela et al. 2006) enfocaram esta espécie característica das florestas estacionais dos estados do Rio de Janeiro e Espírito Santo (Rizzini 1979; Villela et al. 2006) e tão ameaçada. Assim, considerando a importância ecológica e econômica da espécie e a ausência de informações detalhadas sobre sua fenologia, o presente estudo teve como objetivos: (a) descrever os padrões fenológicos de Paratecoma peroba em uma floresta atlântica estacional semidecidual; (b) estabelecer a relação entre a fenologia e as estações seca e chuvosas; e (c) determinar o tamanho mínimo emDAP(diâmetro à altura do peito), em centímetros, dos indivíduos reprodutivos. Essas informações são importantes para a fundamentação de um plano de manejo para a espécie.

\section{Material e Métodos \\ Área de estudo}

A Mata do Carvão possui área de 1.200 ha, localizada ao norte do estado do Rio de Janeiro, no município de São Francisco do Itabapoana, e integra a Estação Ecológica Estadual de Guaxindiba, que abrange área total de 3.260 ha ( $21^{\circ} 24^{\prime}$ 'S e $\left.41^{\circ} 04^{\prime} \mathrm{W}\right)$. A vegetação é classificada como floresta estacional semidecidual de terras baixas, também chamada de mata de tabuleiros (Rizzini 1979). Entre as cinco espécies arbóreas mais importantes podemos destacar Acacia polyphyla (DC.) Benth., Metrodorea nigra A. St.-Hil. var. brevifolia Engl., Paratecoma peroba, Pseudopiptadenia contorta (D.C.) Lewis \& M.P. Lima, Talisia coriacea Radlk. (Villela et al. 2006; Nascimento \& Lima 2008).

O solo da região é classificado como argissolo amarelo-álico com textura arenosa, baixa capacidade de retenção de água e pobre em nutrientes (Villela et al.2006). O clima da regiãoé caracterizado por apresentar sazonalidade, com um período seco que vai de maio a setembro. Segundo o sistema de classificação de Köppen (1948), o clima é do tipo 
Aw, também conhecido por clima de savanas, com inverno seco (precipitação menor do que $60 \mathrm{~mm}$ ) e chuvas concentradas no verão. No período de 1975 a 1989, a precipitação pluviométrica média anual e temperatura média anual foram de $1.023 \mathrm{~mm} \mathrm{e} 24^{\circ} \mathrm{C}$, respectivamente (Oliveira 1996). Entre 1997 a 2007 a precipitação média anual e a temperatura média anual foram de $821,90 \mathrm{~mm} \mathrm{e} 23^{\circ} \mathrm{C}$, respectivamente (Estação Experimental de Campos Pesagro/UENF).

Entre 1960 e 1980 a Mata do Carvão teve sua área reduzida, em função de plantio de cana-deaçúcar, pecuária, comercialização de madeiras (eg. Aspidosperma spp., Copaifera lucens Dwyer, Tabebuia spp. e Paratecoma peroba) e retirada de material lenhoso para a produção de carvão vegetal, passando de cerca de 5.000 ha em 1964 para 1.200 ha em 1986 (Silva \& Nascimento 2001; Nascimento $\&$ Silva 2003). Segundo esses mesmos autores, o fragmento mais representativo de mata sobre tabuleiro no estado do Rio de Janeiro é a Mata do Carvão (Estação Ecológica Estadual de Guaxindiba), atualmente administrada pelo Instituto Estadual do Ambiente (INEA/RJ).

$\mathrm{Na}$ área selecionada para o estudo foram utilizadas quatro parcelas de $50 \mathrm{~m} \times 50 \mathrm{~m}\left(2500 \mathrm{~m}^{2}\right)$, totalizando área de um (1) hectare. Estas parcelas distam cerca de $600 \mathrm{~m}$ da borda da mata Além das parcelas, também foi considerado como área amostral um trecho de $10 \mathrm{~m}$ de cada lado de uma trilha de cerca de 300 m existente no interior da área de floresta selecionada para o estudo. A área não apresenta vestígios aparentes de corte seletivo e de fogo, sendo classificada como área preservada (AP) (Villela et al. 2006).

\section{Acompanhamento fenológico}

Em setembro de 2005 iniciou-se a marcação dos indivíduos de Paratecoma peroba e em outubro do mesmo ano iniciaram-se os estudos fenológicos. Além dos 18 indivíduos de $P$. peroba com diâmetro do tronco a $1,30 \mathrm{~cm}$ do nível do solo (DAP $\geq) 10$ $\mathrm{cm}$, amostrados nas parcelas por Nascimento \& Silva (2001) e Villela et al. (2006), também foram marcados, enumerados e acompanhados indivíduos com $\mathrm{DAP} \geq 4 \mathrm{~cm}$ localizados próximos à trilha $(n=24)$ a fim de se determinar qual seria o diâmetro mínimo (DAP) dos indivíduos reprodutivos (como reprodutivo foi considerado o indivíduo que apresentou botões florais e/ou frutos durante o período de observação).

O acompanhamento fenológico dos 42 indivíduos marcados foi realizado no período de outubro de 2005 a dezembro de 2007, com auxílio de binóculo, durante período diurno (normalmente das 7 às 17 horas). Inicialmente, o acompanhamento foi quinzenal e, após o período de floração, foi mensal. A metodologia de observação fenológica utilizada foi a direta, quantitativa e semi-quantitativa, tanto para as fenofases vegetativas, quanto para as reprodutivas (d'Eça-Neves \& Morellato 2004). O registro do DAP (cm) para cada indivíduo enquadra-se como um dado quantitativo secundário. Para os dados fenológicos quinzenais retirou-se uma média dos valores obtidos para representar cada fenofase no referido mês. As categorias de intensidade das fenofases, em escala ordinal e intervalar, são assim descritas: 0 - nula $=0 \% ; 1$ - baixa $=1$ a $25 \% ; 2$ - regular $=26 \mathrm{a} 50 \% ; 3$ - alta $=51 \mathrm{a} 75 \% ; 4$ - muito alta $=76 \mathrm{a} 100 \%$. Em outubro e novembro de 2008 foram realizadas observações de campo visando registrar a presença ou não de indivíduos em floração.

Para estimar a proporção de frutos em diferentes categorias de acordo com a maturação, foram selecionados, entre os marcados, sete (7) indivíduos com DAP variando entre $24-68 \mathrm{~cm}$ e que estavam nas categorias três (3) e quatro (4) de intensidade de produção de frutos. Os frutos caídos foram coletados mensalmente de abril a novembro de 2006, na serrapilheira sob a copa e dentro de um raio de aproximado de dois metros a partir do tronco. Para a coleta foi utilizado um quadrado metálico de $0,25 \mathrm{~m}^{2}$ alocado em cada um dos quatro quadrantes da copa dos indivíduos norte $(\mathrm{N})$, sul (S), leste (E) e oeste (W), demarcados com uma bússola. Após a coleta, o material foi seco em estufa por dois dias a $80^{\circ} \mathrm{C}$, triado e separado nas seguintes categorias: 1 ) abortos, 2) imaturos, 3) maduros e 4) secos/abertos.

Foram realizadas coletas de material fértil de Paratecoma peroba, que se encontram depositadas no Herbário do Centro de Biociências e Biotecnologia da Universidade Estadual do Norte Fluminense com os números 5585 e 5586.

\section{Análise de dados}

Os dados gerados no campo foram anotados em uma planilha contendo as seguintes informações: número de identificação do indivíduo arbóreo amostrado, DAP (cm), fenofases, escala ordinal (método direto quantitativo) e intervalar (método direto semi-quantitativo) das categorias. Foram descritas nove (9) fenofases para a espécie em estudo, sendo quatro (4) fenofases vegetativas: brotação, folha madura, folha senescente e sem folha e cinco (5) reprodutivas: botão floral, flores 
senescentes, fruto imaturo, fruto maduro e fruto senescente. Como brotação foliar foi considerada tanto a emissão de folhas novas na presença de folhas maduras, quanto à renovação total das folhas, após período de deciduidade. A fenofase senescente para as estruturas foliares e frutíferas foi considerada a partir do instante em que o indivíduo arbóreo apresentou algumas folhas/ frutos senescentes.

O período de floração foi considerado como o período de ocorrência de botões florais na copa das árvores e de flores senescentes recentemente caídas sob a copa. Flores abertas foram de difícil visualização devido à antese iniciar-se por volta das $17 \mathrm{~h}$ estando às flores senescentes (caídas no chão) ao amanhecer ( $7 \mathrm{~h}$ ), fato que impossibilitou o acompanhamento da fenofase de flores abertas. $\mathrm{O}$ início do período de floração de Paratecoma peroba foi constatado após terem sido observadas flores senescentes caídas próximas a algumas árvores. Entretanto, não foram consideradas flores senescentes como uma fenofase, pois os indivíduos apresentaram distribuição muito próxima e assim seria difícil afirmar com precisão de quais indivíduos eram as flores caídas. Esses dados tiveram um caráter qualitativo e auxiliaram no acompanhamento do período reprodutivo da espécie.

Bencke \& Morellato (2002a,b) propuseram duas formas de apresentação dos dados fenológicos, que se baseiam nos métodos diretos semi-quantitativos (a) e qualitativo nominal (b), as quais foram utilizadas neste estudo: (a) Percentual de intensidade de Fournier que avalia a intensidade (em porcentagem) de determinada fenofase em cada indivíduo da população:

$$
\% \text { de Fournier }=\frac{\sum \text { Fournier }}{4 \mathrm{~N}} \times 100
$$

onde $\sum$ Fournier é o somatório das categorias de intensidade de Fournier obtido para todos os indivíduos no mês, dividido pelo valor máximo possível (número total de indivíduos $(\mathrm{N})$ multiplicado por 4). O valor é transformado em valor percentual (multiplicado por 100); (b) Índice de atividade (ou porcentagem de indivíduos) obtido através de dados de presença/ausência de determinada fenofase, avalia a porcentagem de indivíduos da população que estão expressando determinada fenofase. Este método estima a sincronia entre os indivíduos e permite visualizar, mais claramente do que o índice de intensidade, o início e o fim dos períodos de atividade. O evento fenológico é dito como assincrônico (ou não sincrônico) quando 0-20\% de indivíduos manifestam a fenofase; pouco sincrônico, quando 21-60\% de indivíduos manifestam a fenofase e de alta sincronia, quando $61-100 \%$ de indivíduos manifestam a fenofase.

O cálculo das proporções de frutos abortados foi realizado a partir da razão entre frutos caídos atrofiados e/ou mal formados pelo número total de frutos caídos (sadios + atrofiados e/ou mal formados).

Os dados de precipitação pluviométrica mensal e temperatura média mensal do período de estudo foram obtidos na Estação Experimental de Campos (Pesagro), da Universidade Estadual do Norte Fluminense e na Estação Climatológica (Ministério da Agricultura), ambas com distância aproximada de $40 \mathrm{~km}$ da área de estudo.

\section{Resultados \\ Fenofases vegetativas}

Os indivíduos de Paratecoma peroba amostrados apresentaram índices de atividade e intensidade com comportamento semelhante para a fenofase brotamento, com valores variando de $49 \%$ a $100 \%$ em outubro de 2005 e 2006 , e novembro e dezembro de 2007, coincidindo com as primeiras chuvas que marcam o final da estação seca e o início da estação chuvosa (Fig. 1). Nos demais meses (abril de 2006 e janeiro, fevereiro e março de 2007) a sincronia foi alta para o brotamento, indicando que nestes meses a maioria dos indivíduos encontrava-se em fase de brotamento. No entanto, a emissão de folhas novas não foi intensa entre os indivíduos (Fig. 1), haja vista que com a proximidade da estação seca diminuíram consideravelmente os percentuais de atividade e intensidade de brotamento na população, que não apresentou esta fenofase durante todo o período seco (maio a setembro) (Fig. 1).

A população de Paratecoma peroba apresentou alta sincronia para a fenofase folhas senescentes no pico da estação seca (junho a agosto) (Fig. 1). Concomitantemente com a senescência foliar, iniciou-se a perda foliar. Esta fenofase atingiu elevada sincronia (>95\%) no período de julho a outubro (Fig. 1). Picos de maior intensidade, sempre superiores a 70\%, ocorreram principalmente no final da estação seca, nos meses de setembro e outubro (Fig. 1).

Os indivíduos amostrados apresentaram folhas maduras por quase todo o ano, exceto no período seco (julho a outubro), quando esta fenofase foi assincrônica, com intensidade baixa ou nula. 


\section{Fenofases reprodutivas}

No final de setembro de 2005 foi constatado floração de $P$. peroba, observando-se na serrapilheira flores senescentes próximas a alguns indivíduos. No início de outubro de 2005, foram registrados botões florais em número considerável de indivíduos, fato não recorrente nos anos seguintes (2006, 2007 e 2008). Portanto, a floração da $P$. peroba ocorre na transição do período seco para o chuvoso, entre setembro e novembro. Do total amostrado em 2005, 46\% dos indivíduos de $P$. peroba apresentaram botões florais em outubro e $27 \%$ em novembro. As intensidades da fenofase para os meses de outubro e novembro de 2005 foram $20 \%$ e $3 \%$, respectivamente (Fig. 1). As fenofases reprodutivas apresentaram valores de intensidade inferiores a $30 \%$ e, portanto, não houve um pico de intensidade (valores $>50 \%$ ) evidente para as fenofases reprodutivas analisadas (Fig. 1).
Com base nos resultados obtidos, a frutificação foi dividida em três estádios: (a) meses de produção de frutos imaturos: outubro de 2005 a março de 2006 (estação chuvosa); (b) meses de amadurecimento dos frutos: fevereiro a julho de 2006 (final da chuvosa e estação seca); e (c) meses de dispersão das sementes - agosto de 2006 a março 2007 (final da estação seca e estação chuvosa).

A maior atividade para a fenofase fruto imaturo ocorreu no período de dezembro de 2005 a fevereiro de 2006 (54\%). Entretanto, a intensidade para esta fenofase foi inferior a $32 \%$ (Fig. 1).

O amadurecimento dos frutos ocorreu de fevereiro a julho de 2006, com intensidades inferiores a $31 \%$ (Fig. 1). Os meses de maior atividade e intensidade de dispersão de sementes foram agosto, setembro e outubro de 2006, que correspondem ao final da estação seca e início da chuvosa ( $54 \%$ de atividade em todos os meses e intensidades inferiores a $25 \%$ ). Foram
FENOFASES VEGETATIVAS

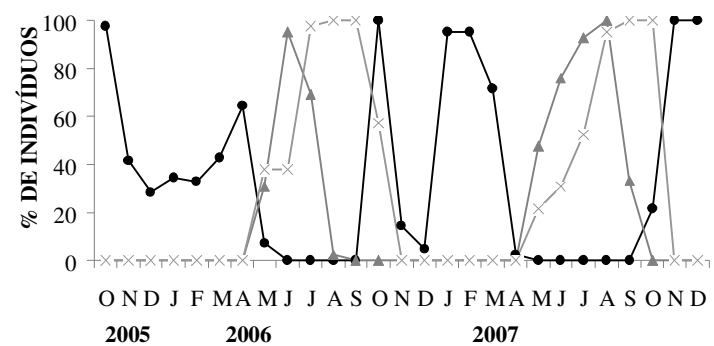

FENOFASES REPRODUTIVAS

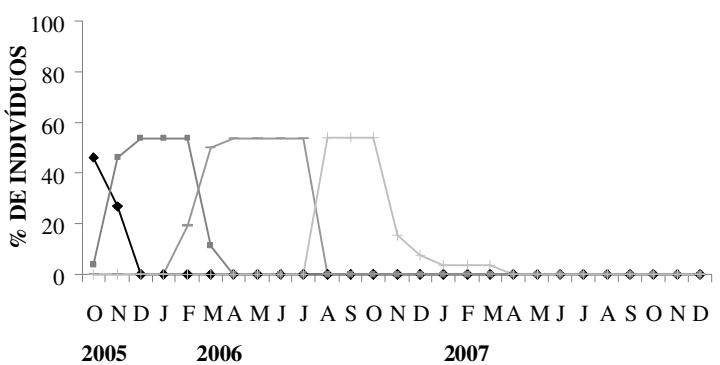

FENOFASES VEGETATIVAS

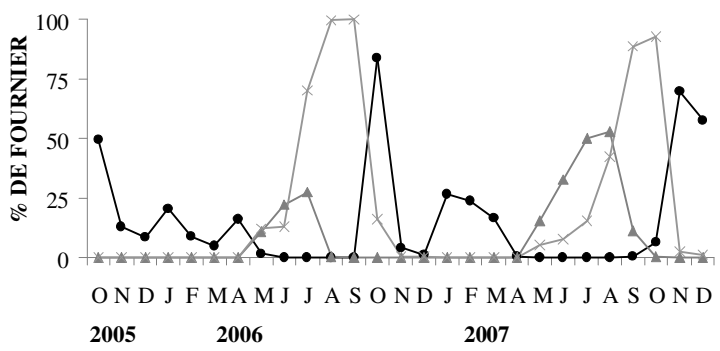

FENOFASES REPRODUTIVAS

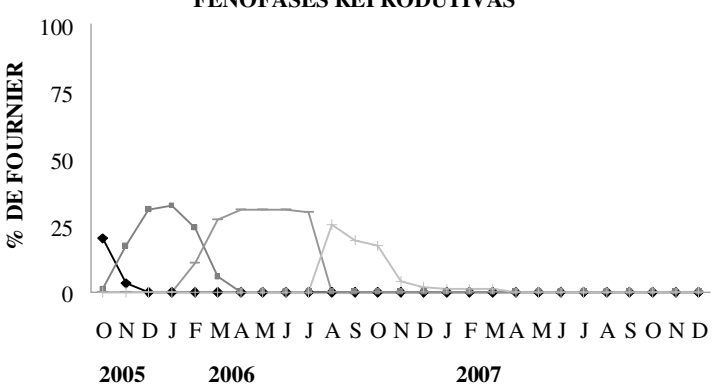

Figura 1 - Fenogramas para o índice de atividade (ou porcentagem de indivíduos) e percentual de intensidade de Fournier, calculado para as fenofases vegetativas e reprodutivas de Paratecoma peroba no período de outubro/2005 a dezembro/2007, na Mata do Carvão (Estação Ecológica Estadual de Guaxindiba), São Francisco do Itabapoana, RJ. Fenofases vegetativas: $\mathbf{O}=$ brotação; $\Delta=$ folha senescente; $\mathbf{x}=$ sem folha e fenofases reprodutivas; $\bullet=$ botão floral; $=$ = fruto imaturo; - = fruto maduro; $+=$ fruto senescente.

Figure 1 - Phenograms of percentage of individuals and intensity of Fournier for the vegetative and reproductive phenophases of Paratecoma peroba from October/2005 to Dezember/2007, in Carvão forest (Guaxindiba State Ecological Station), São Francisco do Iatabapoana, RJ, Brazil. Vegetative phenophases: $\mathbf{O}=$ leaf flush; $\Delta=$ senescent leaves; $\mathrm{x}=$ leaf fall and reproductive phenophases; - floral bud; = imature fruit; - = mature fruit; + = senescent fruit. 
constatados frutos senescentes nos indivíduos amostrados até o mês de março de 2007 (Fig. 1).

Através da análise da proporção de frutos em diferentes categorias de maturação pode-se constatar que a categoria que se destacou foi a de frutos abertos, representando $86 \%$ do total de frutos coletados contra uma porcentagem de $7 \%$ de frutos abortados (Fig. 2).

\section{Relação entre o DAP e o tamanho mínimo dos indivíduos reprodutivos de Paratecoma peroba}

A análise da relação entre o tamanho dos indivíduos (DAP) com o número de indivíduos que apresentaram fenofases reprodutivas mostrou que somente os indivíduos de com DAP $\geq 16 \mathrm{~cm}$ apresentaram fenofases reprodutivas durante $\mathrm{o}$ período de estudo (Fig. 3). Estes indivíduos foram considerados como reprodutivos ou adultos. Portanto, de um total de 42 indivíduos amostrados, 26 indivíduos foram considerados adultos. Destes, 15 indivíduos apresentaram fenofases reprodutivas, o que correspondeu a $58 \%$ dos indivíduos adultos (Fig. 3). A categoria de DAP $>30 \mathrm{~cm}$ foi a que apresentou maior proporção de indivíduos reprodutivos $(73,3 \%)$, demonstrando que

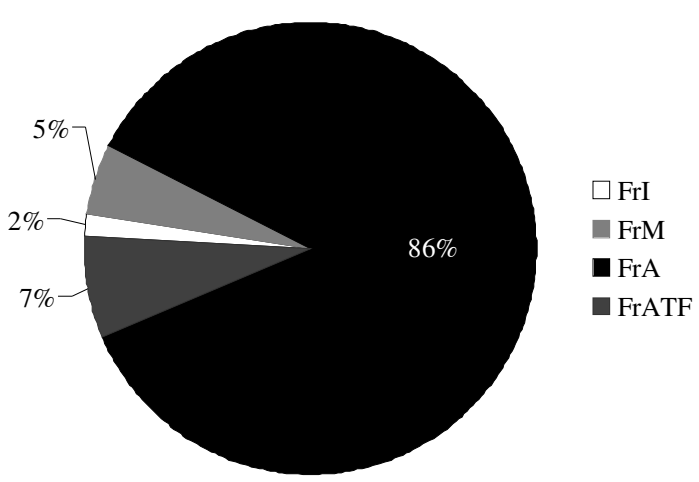

Figura 2 - Proporção de frutos de Paratecoma peroba coletados na serrapilheira em 28 quadrados de $0,25 \mathrm{~m}^{2}$ alocados sob a copa de sete (7) árvores em quatro (4) quadrantes, Mata do Carvão (Estação Ecológica Estadual de Guaxindiba), São Francisco de Itabapoana, RJ. FrI = frutos imaturos; FrM = frutos maduros; FrA = frutos abertos; FrATF $=$ frutos atrofiados ou abortados. Figure 2 - Fruit proportion of Paratecoma peroba sampled in litterfall beneath the crowns of Paratecoma peroba $(\mathrm{n}=7)$, Mata do Carvão, Guaxindiba State Ecological Station, São Francisco de Itabapoana, RJ, Brazil. FrI = imature fruits; FrM $=$ mature fruits; $\mathrm{FrA}=$ open fruits; FrATF $=$ aborted fruits. indivíduos de $P$. peroba tornam-se efetivamente reprodutivos somente quando adquirem grande porte (diâmetros elevados) (Fig. 3).

\section{Discussão}

A ocorrência de elevada sincronia e intensidade da fenofase brotamento foliar observada entre os indivíduos de Paratecoma peroba no início da estação chuvosa corrobora os dados encontrados para outras espécies vegetais de florestas estacionais semideciduais (Morellato \& Leitão-Filho 1990; Santos \& Takaki 2005). Morellato et al. (1989) e Morellato \& Leitão-Filho (1990) ressaltaram a importância das primeiras chuvas, após período de seca, como um fator desencadeador do brotamento. O fluxo sazonal da emissão foliar é um traço bem característico de florestas tropicais sob clima sazonal, até mesmo para evitar que a produção de folhas novas ocorra em época desfavorável (Frankie et al. 1974; Santos \& Takaki 2005). Apesar disso, foram observados alguns indivíduos com baixa produção de folhas novas fora do pico de outubro (meses de abril de 2006 e entre os meses de janeiro a março de 2007). Este fato pode estar ligado a alguma variação microclimática, que poderia vir a interferir no tempo de resposta fenológica de alguns indivíduos arbóreos. Segundo Borchet (1999) as mudanças foliares tornam-se menos dependentes da sazonalidade climática, com o aumento do suprimento hídrico no solo, que diminui o estresse hídrico sazonal.

No presente estudo, Paratecoma peroba apresentou padrão típico de espécies decíduas, que segundo Morellato et al. (1989), caracteriza-se pela perda e produção de folhas concentradas em determinado período e pela permanência de indivíduos sem folhas durante alguns meses. Apesar disso, encontrou-se registro na literatura desta espécie como brevidecídua (Engel 2001). A atividade de senescência e queda foliar altamente sincrônica observada para $P$. peroba é uma característica que tem sido relatada para várias outras espécies da mesma família, principalmente os ipês (Tabebuia spp.) (Justiniano \& Fredericksen 2000; Palioto et al. 2007). Frankie et al. (1974) indicaram que as condições xéricas do ambiente seriam responsáveis pela queda foliar e que a quantidade e taxa de perda foliar seriam determinadas pela severidade da estação seca. Esses mesmos autores ressaltaram a importância dos períodos de perda foliar para a dinâmica dos 
microrganismos da serrapilheira. Villela et al. (2006), ao avaliarem o efeito do corte seletivo na ciclagem de nutrientes na Estação Ecológica Estadual de Guaxindiba, verificaram que a maior concentração de nutrientes no estoque (serrapilheira) ocorreu, principalmente durante meados da estação seca, como conseqüência do grande número de árvores perdendo folhas e da baixa taxa de decomposição durante esta estação. A perda de folhas no final da estação seca parece ser decorrente da baixa umidade relativa do ar e do solo. Sendo assim, durante a estação seca, as condições para absorção de nutrientes no solo ficariam prejudicadas (ar muito seco e diminuição do potencial hídrico do solo) e as espécies tenderiam a perder suas folhas, diminuindo a evapotranspiração (Nunes et al. 2005). Segundo Addicott (1978), dentre os benefícios da perda foliar está a manutenção da homeostase, que garante o balanço hídrico da planta com o meio em que ela se encontra.

Durante os anos de observação deste estudo (2005-2008) registrou-se floração em massa, nos indivíduos de Paratecoma peroba, apenas em 2005. Estudos realizados anteriormente na Mata do Carvão (1995-2001) não detectaram grande número de indivíduos desta espécie apresentando fenofases reprodutivas (Nascimento M.T, dados não publicados). O primeiro registro de floração, desde 1995, ocorreu em 1998, porém restrita a poucos indivíduos. Em 2004, foi observada uma nova floração (Aguiar W., comunicação pessoal), porém também de baixa ocorrência e intensidade. Segundo a classificação de Newstrom et al. (1994), quando há ocorrência de apenas um ciclo reprodutivo em um intervalo de vários anos, ou seja, ano de intensa reprodução, seguido por anos de baixa ou nenhuma reprodução, este padrão é definido como supra-anual. Assim, estes resultados sugerem padrões de floração e frutificação supra-anuais para $P$. peroba na Mata do Carvão, embora Engel (2001) tenha descrito esta espécie como sendo anual irregular.

Segundo a classificação proposta por Gentry (1974), a floração de Paratecoma peroba foi identificada como estratégia "big bang”, um padrão tipicamente tropical, caracterizada por depender do comportamento oportunista dos polinizadores, os quais são atraídos pela nova fonte de néctar. Esta estratégia, em Bignoniaceae, apresenta alto sincronismo intrapopulacional, com duração de poucos dias, e ocorre apenas na estação seca (Gentry 1974).

A floração da Paratecoma peroba ocorreu na transição do período seco para o chuvoso, o que

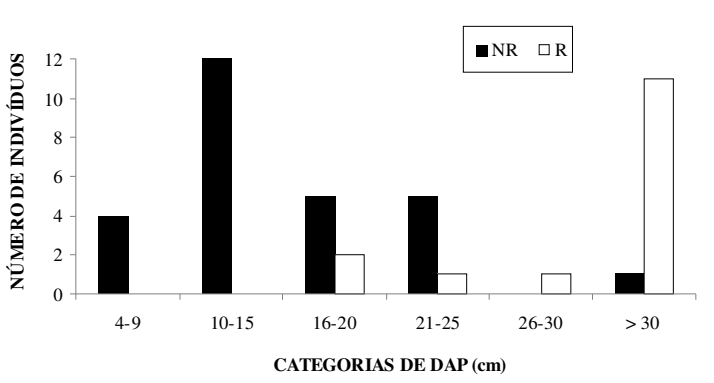

Figura 3 - Número de indivíduos reprodutivos e não reprodutivos de Paratecoma peroba em diferentes classes diamétricas $(\mathrm{cm})$ na Mata do Carvão (Estação Ecológica Estadual de Guaxindiba), São Francisco do Itabapoana, RJ. NR = não reprodutivos; $\mathrm{R}=$ reprodutivos.

Figure 3 - Number of reproductive and non-reproductive individuals of Paratecoma peroba distributed into diametric classes (cm) in the Carvão forest, Guaxindiba State Ecological Station, São Francisco de Itabapoana, RJ, Brazil. NR = non reproductive; $\mathrm{R}=$ reproductive.

corrobora o estudo de Engel (2001) para a mesma espécie. Alguns estudos apontam aspectos favoráveis para a ocorrência da floração neste período, tais como início das chuvas e aumento da temperatura, contribuindo para o aumento na taxa de decomposição da serrapilheira, maior disponibilidade de nutrientes para as plantas (Pedroni et al. 2002), não ocorrência de chuvas pesadas que poderiam danificar as estruturas florais e redução da atividade de herbívoros (Morellato et al. 1989; Nunes et al. 2005).

A floração e o brotamento foliar foram eventos fenológicos simultâneos. Este padrão também é descrito para outras espécies em florestas tropicais estacionais (Morellato \& Leitão Filho 1990; Santos \& Takaki 2005). Morellato et al. (1989) consideraram que a precipitação, após período de estresse hídrico, seria o principal fator desencadeador tanto para floração, como para o brotamento foliar.

O período de frutificação de Paratecoma peroba foi longo, cerca de um ano, com os primeiros frutos tendo se estabelecido no início da estação chuvosa (novembro 2006) e a completa maturação e dispersão ocorrendo no início da estação chuvosa seguinte (novembro 2007). Este padrão corrobora o resultado encontrado por Engel (2001) para esta mesma espécie, como também, para diferentes espécies vegetais realizados em florestas tropicais estacionais (Dias \& Oliveira Filho 1996; Pedroni et al. 2002). Constatou-se, que a formação dos frutos imaturos corresponde aos meses mais quentes e 
úmidos. Este fato pode estar relacionado com o período de assimilação, reserva e alocação de recursos pela planta para otimizar a produção de frutos (Morellato \& Leitão Filho 1990). Por outro lado, os frutos maduros estão relacionados aos meses de transição da estação chuvosa para seca. A estação seca contribui para o processo de perda de umidade que acompanha a maturação de frutos em algumas famílias, dentre elas, Bignoniaceae (Janzen 1967). Ferraz et al. (1999) e Santos \& Takaki (2005) apontaram diversos estudos que relacionam a época de produção de frutos, o tipo de fruto (seco ou carnoso) e a síndrome de dispersão das sementes. Morellato et al. (1989) citam que a frutificação na estação seca tem sido relacionada com a dispersão pelo vento, que auxilia na dispersão de sementes.

A taxa de $7 \%$ de frutos abortados (mal formados) pode ser considerada baixa ou dentro do limite inferior observado para árvores em florestas tropicais (Palleiro et al. 2006). Entretanto, vale ressaltar que esse dado pode estar subestimado, uma vez que este dado não foi obtido a partir da porcentagem de flores fecundadas que não produziram frutos maduros. Bawa (1974) apud Bawa \& Webb (1984) registrou, para a espécie Tabebuia rosea DC. (Bignoniaceae) elevadas taxas de aborto (99\%), expresso como a porcentagem de flores que não desenvolveram frutos maduros.

O aborto de frutos normalmente está relacionado à limitação de recursos que seriam captados pela árvore, à origem e qualidade do pólen, a um evento de herbivoria e/ou parasitismo do fruto, à baixa diversidade genética da população e/ou à autofecundação (Sampaio \& Almeida 1995; Díaz et al. 2003; Spironello et al. 2004; Palleiro et al. 2006). $\mathrm{O}$ aborto de frutos também é apontado como uma forma de a planta parental remover seletivamente propágulos com baixa viabilidade, apontado por Bawa \& Webb (1984) como a principal causa do aborto de frutos, embora ressaltem que poucos estudos têm sido desenvolvidos neste âmbito. Díaz et al. (2003) destacaram que gametas e/ou zigotos abortados não representam eventos ao acaso, ou seja, gametas e propágulos com fenótipos irregulares normalmente caracterizam frutos abortados, enquanto propágulos bem sucedidos (ou que germinaram) possuem fenótipos regulares.

O período no qual as árvores encontravamse desfolhadas coincidiu com a dispersão das sementes de $P$. peroba, que possui o vento como principal agente dispersor (anemocoria). Morellato \& Leitão Filho (1990) observaram que a queda foliar e as atividades reprodutivas ocorreram no mesmo período indicando que existe uma relação entre a queda foliar, a síndrome de dispersão e a posição no estrato. Morellato et al. (1989) também indicaram que a queda foliar esteve associada, principalmente, com a dispersão de diásporos em espécies anemocóricas. Frankie et al. (1974) encontraram resultado semelhante para espécies vegetais de Floresta Seca na Costa Rica.

A maioria dos indivíduos adultos enquadrouse na classe de DAP $>30 \mathrm{~cm}(73,3 \%)$, demonstrando que indivíduos desta espécie somente tornam-se reprodutivos quando atingem grande porte. Mantovani et al. (2003) verificaram que a floração e a frutificação dependem tanto de características do ambiente, quanto da espécie e de seu estádio de desenvolvimento. Ao relacionarem o DAP (mínimo, máximo e médio) de 19 espécies arbóreas com a porcentagem de plantas que floresceram, verificaram que em várias espécies o início da floração ocorre com diferentes DAPs. O fato de a maioria dos indivíduos reprodutivos de $P$. peroba apresentarem DAP $>30 \mathrm{~cm}$, que é superior ao tamanho médio adotado para o corte seletivo na região (DAP> $20 \mathrm{~cm}$ ) (Villela et al. 2006), e, somando a um padrão fenológico reprodutivo supra-anual, implica que muitos indivíduos não tiveram chance de se reproduzir ou tiveram poucos eventos de reprodução antes do corte. Este dado reforça a necessidade de maior controle e fiscalização nesta Unidade de Conservação visando coibir o corte seletivo de madeira. Estas informações também poderão ser muito úteis na definição de estratégias de manejo e produção de sementes de $P$. peroba. Estudos comparativos com outras áreas em que tenham sido detectadas perturbações e estudos envolvendo a genética e ecologia reprodutiva desta espécie poderão elucidar questões sobre fluxo gênico e variabilidade genética das populações, assim como fornecer subsídios para o manejo florestal de Paratecoma peroba.

\section{Agradecimentos}

À Universidade Estadual do Norte Fluminense (UENF) o apoio logístico. B.L.A.Lins agradece ao CNPq a bolsa de Iniciação Científica e MTN a bolsa de produtividade científica. Ao professor E.F. Souza (LEAG, CCTA/UENF) o fornecimento dos dados climatológicos; ao setor de geoprocessamento (LCA, CBB/UENF) a imagem da área de estudo; ao W.M. Aguiar o auxílio com a marcação de indivíduos arbóreos de $P$. peroba nas trilhas e as informações de anos anteriores sobre a floração (ano de 2004); aos técnicos José Vanderley Rangel, Helmo Siqueira e 
Gerson Rocha o apoio nos trabalhos de campo. Aos dois revisores anônimos as valiosas sugestões apresentadas no manuscrito.

\section{Referências}

Addicott, F.T. 1978. Abscission strategies in the behavior of tropical trees. In: Tomlinson, P.B. \& Zimmerman, M.H. (eds.). Tropical trees as living systems. Cambridge University Press, Cambridge. Pp. 381-398.

Alcantara, S. \& Lohmann, L.G. 2010. Evolution of floral morphology and pollination system in Bignonieae (Bignoniaceae). American Journal of Botany 97: 1-15.

Andreis, C.; Longhi, S.J.; Brun, E.J.; Wojciechowski, J.C.; Machado, A.A.; Vaccaro, S. \& Cassal, C.Z. 2005. Estudo fenológico em três fases sucessionais de uma Floresta Estacional Decidual no município de Santa Tereza, RS, Brasil. Revista Árvore 29: 55-63.

Bawa, K.S. \& Webb, C.J. Flower. 1984. Fruit and seed abortion in tropical forest trees: implications for the evolution of paternal and maternal reproductive patterns. American Journal of Botany 71: 736-751.

Bencke, C.S.C. \& Morellato, L.P.C. 2002a. Estudo comparativo da fenologia de nove espécies arbóreas em três tipos de floresta atlântica no sudeste do Brasil. Revista Brasileira de Botânica 25: 237-248.

Bencke, C.S.C. \& Morellato, L.P.C. 2002b. Comparação de dois métodos de avaliação de fenologia de plantas, sua interpretação e representação. Revista Brasileira de Botânica 25: 269-275.

Borchert, R. 1999. Climatic periodicity, phenology and cambium activity in tropical dry forest trees. IAWA Journal 20: 239-247.

d’Eça-Neves, F.F. \& Morellato, L.P.C. 2004. Métodos de amostragem e avaliação utilizados em estudos fenológicos de florestas tropicais. Acta Botanica Brasilica 18: 99-108.

Dias, H.C.T. \& Oliveira-Filho, A.T. 1996. Fenologia de quatro espécies arbóreas de uma Floresta Estacional Semidecídua Montana em Lavras, MG. Cerne 2: 66-88.

Díaz, M.; Møller, A.P. \& Pulido, F.J. 2003. Fruit abortion, developmental selection and developmental stability in Quercus ilex. Oecologia 135: 378-385.

dos Santos, G. \& Miller, R.B.. 1992. Wood anatomy of Tecomeae. In: Gentry, A.H. (ed.). Flora Neotropica Monograph. 25. New York Botanical Garden, Bronx. Pp. 336-358.

Engel, V.L. 2001. Estudo fenológico de espécies arbóreas de uma floresta tropical em Linhares, ES. Tese de Doutorado. Universidade Estadual de Campinas, Campinas.

Ferraz, D.K.; Artes, R.; Mantovani, W. \& Magalhães, L.M. 1999. Fenologia de árvores em fragmento de mata em São Paulo, SP. Revista Brasileira de Biologia 59: 305-317.

Frankie, G.W.; Baker, H.G. \& Opler, P.A. 1974. Comparative phenological studies of trees in tropical wet and dry forests in the lowlands of Costa Rica. Journal Ecology 62: 881-913.

Gentry, A.H. 1974. Flowering phenology and diversity in tropical Bignoniaceae. Biotropica 6: 64-68.

Gentry, A.H. 1980. Bignoniaceae - Part I: Crescentieae and Tourrettieae. Flora Neotropica Monograph 25. New York Botanical Garden, Bronx.

Gentry, A.H. 1992. A synopsis of Bignoniaceae ethnobotany and economic botany. Annals of the Missouri Botanical Garden 79: 53-64.

Janzen, D.H. 1967. Synchronization of Sexual reproduction of trees within the dry season in Central America. Evolution 21: 620-637.

Justiniano, M.J. \& Fredericksen, T.S. 2000. Phenology of trees species in Bolivian Dry Forests. Biotropica 32: 276-281.

Köppen, W. 1948. Climatologia: com um estúdio de los climas de La tierra. Fondo de Cultura Económica, México. 479p.

Lorenzi, H. 2000. Árvores Brasileiras: Manual de identificação e cultivo de plantas arbóreas nativas do Brasil. $3^{\mathrm{a}}$ ed. Vol. 2. Instituto Plantarum de Estudos da Flora, Nova Odessa. 352p.

Mantovani, M.; Ruschel, A.R.; Reis, M.S.S.; Puchalski, A. \& Nodari, R.O. 2003. Fenologia reprodutiva de espécies arbóreas em uma formação secundária da floresta atlântica. Revista Árvore 27: 451-458.

Morellato, L.P.C.; Rodrigues, R.R.; Leitão Filho, H.F. \& Joly, C.A. 1989. Estudo comparativo da fenologia de espécies arbóreas de floresta de altitude e floresta mesófila semidecídua na Serra do Japi, Jundiaí, São Paulo. Revista Brasileira de Botânica 12: 85-98.

Morellato, L.P.C. \& Leitão Filho, H.F. 1990. Estratégias fenológicas de espécies arbóreas em Floresta Mesófila na Serra do Japi, Jundiaí, São Paulo. Revista Brasileira de Biologia 50: 163-173.

Nascimento, M.T. \& Silva, F.L. 2003. Avaliação da taxa de desmatamento no período de 1986 a 2002 na Estação Ecológica Estadual de Guaxindiba (Mata do Carvão), São Francisco do Itabapoana, RJ. In: Anais do VI Congresso de Ecologia do Brasil, Fortaleza. Pp. 127-128.

Nascimento, M.T. \& Lima, H.C. 2008 Floristic and Structural Relationships of a Tabuleiro Forest in Northeastern Rio de Janeiro, Brazil. In: Thomas, E. The Atlantic Coastal Forest of Northeastern Brazil. Memoirs of the New York Botanical Garden 100: 395-416.

Newstrom. L.E.; Frankie, G.W. \& Baker, H.G. 1994. A new classification for plant phenology based on flowering patterns in Lowland Tropical Rain Forest trees at La Selva, Costa Rica. Biotropica 26: 141-159.

Nunes, Y.R.F.; Fagundes, M.; Santos, R.M.; Domingues, E.B.S.; Almeida, H.S. \& Gonzaga, A.P.D. 2005. Atividades fenológicas de Guazuma ulmifolia Lam. (Malvaceae) em uma floresta estacional decidual no norte de Minas Gerais. Lundiana 6: 99-105. 
Oliveira, V.P.S. 1996. Avaliação do sistema de irrigação por sulco da fazenda do Alto em Campos, RJ. Tese de Mestrado. Universidade Estadual Norte Fluminense, Campos dos Goytacazes.

Olmstead, R.G.; Zjhra, M.L.; Lohmann, L.G.; Grose, S.O. \& Eckert, A.J. 2009. A molecular phylogeny and classification of Bignoniaceae. American Journal of Botany 96: 1731-1743.

Palioto, G.F.; Sugioka, D.K.; Coda, J.; Zampar, R.; Lazarin, M.O.; Loyola, M.B.P. \& Rubin Filho, C.J. 2007. Fenologia de espécies arbóreas no campus da Universidade Estadual de Maringá. Revista Brasileira de Biociências 5: 441-443.

Palleiro, N.; Mandujano, M.C. \& Golubov, J. 2006. Aborted fruits of Opuntia microdasys (Cactaceae): insurance against reproductive failure. American Journal of Botany 93: 505-511.

Pedroni, F.; Sanchez, M. \& Santos, F.A.M. 2002. Fenologia da copaíba (Copaifera langsdorfii Desf. Leguminosae, Caesalpinioideae) em uma floresta semidecídua no sudeste do Brasil. Revista Brasileira de Botânica 25: 183-194.

Reys, P.; Galetti, M.; Morellato, L.P.C. \& Sabino, E.J. 2005. Fenologia reprodutiva e disponibilidade de frutos de espécies arbóreas em mata ciliar no rio Formoso, Mato Grosso do Sul. Biota Neotropica 5: 1-6.

Rizzini, C.T. 1979. Tratado de Fitogeografia do Brasil. HUCITEC, São Paulo. 747p.
Sampaio, E.S. de \& Almeida, A.A. de. 1995. Morfologia floral e biologia reprodutiva de Pyrostegia venusta (Bignoniaceae) na região urbana de Curitiba, Paraná. Acta Biológica Paranaense 24: 25-38.

Santos, D.L. \& Takaki, M. 2005. Fenologia de Cedrela fissilis Vel. (Meliaceae) na região rural de Itirapina, SP, Brasil. Acta Botanica Brasilica 19: 625-632.

Scudeller, V.V.; Vieira, M.F. \& Carvalho-Okano, R.M. de. 2008. Distribuição espacial, fenologia da floração e síndrome floral de espécies de Bignonieae (Bignoniaceae). Rodriguésia 59: 297-307.

Silva, G.C. \& Nascimento, M.T. 2001. Fitossociologia de um remanescente de mata sobre tabuleiros no norte do estado do Rio de Janeiro (Mata do Carvão). Revista Brasileira de Botânica 24: 51-62.

Spironello, W.R.; Sampaio, P.T.B. \& Ronchi-Teles B. 2004. Produção e predação de frutos em Aniba rosaeodora Ducke var. amazonica Ducke (Lauraceae) em sistema de plantio sob floresta de terra firme na Amazônia Central. Acta Botanica Brasilica 18: 801-807.

Talora, D.C. \& Morellato, P.C. 2000. Fenologia de espécies arbóreas em floresta de planície litorânea do sudeste do Brasil. Revista Brasileira de Botânica 23:13-26.

Villela, D.M.; Nascimento, M.T.; Aragão, L.E.O.C. \& Gama, D. M. 2006. Effect of selective logging on forest structure and nutrient cycling in a seasonally dry Brazilian Atlantic forest. Journal of Biogeography 33: 506-516. 